\title{
Teaching Reform Analysis of Computer Composition Principle Course Based on OBE
}

\author{
Hui Wang ${ }^{1, a}$, Mao Lu ${ }^{1, b}$ and Gang Liu ${ }^{1, c^{*}}$ \\ ${ }^{1}$ College of Computer Science and Engineering, Changchun University of Technology, Changchun, \\ China \\ âwanghui1982@ccut.edu.cn, blumao@ccut.edu.cn, ${ }^{*}$ liugang@ccut.edu.cn
}

\begin{abstract}
Keywords: Outcomes-based Education; Computer Composition Principle; Teaching Reform
\end{abstract}
\begin{abstract}
OBE education is an outcomes-based education model, and it is the development trend of computer composition principle course teaching. This article introduces the OBE education concept into the computer composition principle course, and discusses the OBE-based computer composition principle teaching reform method. This article mainly discusses the method of optimizing the course teaching content based on the learning result, establishing a diversified and standardized evaluation mode method, and using multiple methods such as network teaching to collect student process data. OBE's education concept, as an innovation to the traditional education model, adapts to the development of the era. Its application in the computer composition principle course will help improve students' mastery of the computer composition principle course, and will lay a good foundation for subsequent professional study and computer professional graduate entrance examination.
\end{abstract}

\section{Introduction}

The engineering education professional certification is based on the concept of Outcome based education (OBE) and carries out the personnel training system construction. Its emphasis on cultivating students' ability to solve complex engineering problems is an important guarantee for improving the quality of engineering personnel training. It is also an important basis for China's higher education to participate in international competition. OBE education concept originated in the United States, and gradually adopted by many developed and developing countries, has gradually become the basis for the training of engineering education personnel [2]. It uses the student's learning outcome to drive the entire course activity, emphasizing the student's learning results, and using this as an important factor to feedback the quality of teaching activities [3-4].

\section{Analysis of Characteristics and Present Situation of Computer Composition Principle Course}

The principle of computer composition is the core basic course of computer science. It plays a role in the various courses of computer science. It is one of the subjects for the entrance examination for computer majors. Its importance is self-evident [5-6]. The course mainly includes the basic components of the computer stand-alone system hardware and the working principle of the various functional components, data representation and calculation principle, instruction structure and execution principle, memory work and expansion principle, etc. It is a course that emphasizes the working principle of each core functional component that explains the work of a single system. Through various calculations, it aims to make students thoroughly understand the working principle of various functional components of the computer.

However, the present situation is that when students are learning this course, they often feel that they have more knowledge, are difficult to remember, and the working principle is difficult to understand. The reason is that students do not think enough about the working methods of the various functional parts of the computer, and there are many phenomena of rote memorization of knowledge. Many students' learning purposes are not clear, they only deal with the examinations, and it is inevitable that they will not move their brains during class. Back, the phenomenon of forgetting all light after the exam. 
Traditional teaching methods emphasize teacher-centered teaching. Teachers teach according to the progress of teaching. They ignore the fundamental goal of "learning results" of students. They have a single form of learning and lack for cultivating students' abilities in reasoning and evaluation. The effect is necessarily poor. In addition, the traditional computer composition principle course uses the teaching content to drive the teaching process, and the evaluation method is lagging behind which is difficult to give correct and effective evaluation to students' learning results. In order to meet the needs of China's engineering education, combined with the requirements and characteristics of the training of applied undergraduate talents in local engineering colleges, we have introduced the OBE education concept in the construction of the principle of computer composition. It is oriented to the learning results, student-centered, and collaborative teaching. From the aspects of teaching objectives, teaching content, teaching methods, student evaluation, etc., the OBE-based computer composition principle course teaching reform and exploration are carried out.

\section{The Method of Computer Composition Principle Course Construction under OBE Education Mode}

Optimizing the Contents and Methods of Course Teaching Guided by Learning Results. In accordance with the need to support the graduation of "complex engineering problems", the content of the theoretical courses is arranged and the learning tasks are designed. The teaching method based on the OBE education concept is to take the expected learning outcome as a goal, and reverse design related teaching activities through the outcome of the output. According to the characteristics of computer composition principle courses, determine the contribution of the course to professional graduation requirements, specify the teaching objectives, refine the expected learning outcomes for evaluation, and then design learning tasks around the learning objectives, complete learning objectives and learning task matrix, and optimize theoretical teaching process, stimulates students' interest and motivation in learning, improves teaching efficiency and improves teaching effectiveness. In the learning task design process, we comprehensively consider the knowledge points or ability points that students should have, and use classroom teaching, assignments, design topics, group discussion, and other forms. From the feedback of students' learning effects, the difficulty of the computer composition principle is largely due to the fact that students do not fully understand why computers work this way. According to the OBE theory, we need to reverse design this part of the teaching content and teaching methods. In teaching methods, teachers should pay attention to guide students to think about this, and appropriately increase the relevant group discussion or design topic, in the course of the completion of the topic, the students will gradually understand the working principle of the computer.

Based on Learning Results, Establish a Diversified and Standardized Evaluation Model. A scientific and reasonable assessment of the achievement of a course goal can identify students' shortcomings in the learning process, thereby contributing to the continuous improvement of teaching methods. For different types of learning tasks, comprehensive consideration of student completion progress, concept mastery, correctness of problem solving, and self-design ability should be used to design the achievement criteria of the course objectives, and to refine the scoring criteria. The task implementation method and the design of specific scoring standards are the key to the implementation of scientific and reasonable assessment. In this way, we can get each student's learning situation of a detailed knowledge and ability in the entire course, and then get the average learning situation of all the students. Through the analysis of the learning results of the set knowledge objectives and the ability goals, the actual learning outcome of this course can be evaluated, and reflection and continuous improvement can be carried out.

Multiple Ways to Collect Student Learning Process Data, Continuous Improvement of Teaching Activities. While collecting offline student learning data, we are actively building online learning courses. This can be combined online and offline to collect large-scale learning data. The computer composition principle online course construction, can use the Internet platform to effectively collect large-scale data in the student learning process, and carry out effective collation, analysis and induction, to make up for the shortcomings of the simple offline course data collection is small, inductive 
collation difficult. The construction of online courses not only makes use of big data technology and intelligent algorithms to personalize students' learning, but also pushes the learning content and test questions in a targeted manner according to the weak problems reflected in the students' learning. This effectively improves learning efficiency. It enables teachers to conduct more targeted instructional design based on the results of data analysis, continuous teaching reform, and promotion of offline teaching.

\section{Summary}

OBE's educational concept has an important and realistic guiding significance as an innovation to the traditional education model, guided by the student's expected learning outcomes, adapting to the development of the times, optimizing the teaching content, updating the teaching methods, and setting the evaluation system rationally. Based on the concept of OBE, this article discusses the method of teaching reform in the principle of computer composition. In the future, the OBE concept will be used in the construction of the curriculum of related courses to lay the foundation for further developing the OBE education model in teaching.

\section{Acknowledgements}

The authors acknowledge the project of the Higher Education Institute of Jilin (Grant: JGJX2017D57).

\section{References}

[1] Y. F. Liu, D. Z. Xu, L. D. Liang, H. Yu, M. Zhao. Exploration and Practice of Teaching Reform of "Calculation Method "Based on OBE Concept in Science and Engineering Major. Education Teaching Forum, 2018, No. 9, p. 135.

[2] J. F. Qiou, E. Z. Zhu, Y. Zhou, H. Zhong. Operating System Course Teaching Reform Under OBE Education Mode. Computer Education, 2015, No. 12, p. 28.

[3] Z. Y. Li, H. Zhu, Z. J. Liu, Y. J. Xia. Guiding the Reform of Higher Engineering Education with Result-oriented Educational Ideas. Research on Higher Engineering Education, 2014, No. 2, p. 29.

[4] Q. F. Shi. Exploration of Teaching Reform of Programming Course Based on OBE. Computer Education, 2016, No. 3, p. 106.

[5] J. Zhou. Discussion on Teaching Reformation of Computer Composition Principle. Journal of Southwest China Normal University (Natural Science Edition), Vol. 39 2014, No.6, p.161.

[6] D. Q. Li, Y. Xu, H. Chang. Research and Exploration on Teaching Reform of Computer Composition Principle Course. Computer Knowledge and Technology, Vol. 13, 2017,No. 3, p. 107. 